\title{
Can MiR-503 be used as a marker in diabetic patients with ischemic stroke?
}

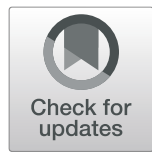

\author{
Saba Sheikhbahaei ${ }^{1}$ (D), Danesh Manizheh², Saadatnia Mohammad ${ }^{3}$, Tajaddini Mohamad Hasan ${ }^{4}$, Nazemian Saman ${ }^{5}$,
} Rafiee Laleh ${ }^{4}$, Motieian Mahsa ${ }^{6}$, Amoushahi Khouzani Sanaz ${ }^{2}$ and Haghjooy Javanmard Shaghayegh ${ }^{4 *}$

\begin{abstract}
Background: Some microRNAs are involved in diabetes pathology and some are known to have role in stroke. MiR-503 causes endothelial dysfunction in diabetic patients, predisposing to ischemia. There has been no study evaluating Mir-503 level in diabetic patients with or without ischemic stroke.

Methods: We designed a cross-sectional study to assess and compare serum level of MiR-503 in 4 groups of diabetic patients with ischemic stroke (I), non-diabetic patients with stroke (II), diabetic patients (III), and healthy controls (IV) in acute phase and 3 months later.

Results: Our data analysis showed that mean relative expression of MiR-503 in group (I) was significantly higher than 3 other groups $(p<0.05)$. The level of miR-503 was related to the patients' fasting blood glucose, Cholesterol level, NIHSS score and acute-phase modified Rankin Scale (mRS) $(r=0.49, p=0.001, r=0.5, p=0.009, r=0.45$, $p=0.009, r=0.48, p=0.003, C l=95 \%$ ). Relative expression of miR in patients with $\mathrm{mRS} \leq 2$ (good outcome) was lower than in patients with $\mathrm{mRS}>2$ (poor outcome) $(p=0.008)$. After 3 months, level of miR decreased significantly only in group (I) ( $p=0.002)$. Mean relative expression of miR-503 in chronic phase was not significantly different among groups ( $p$-value> 0.05 ). There was no relation between miRNA level and mRS in chronic phase.

Conclusion: Hyperglycemia and ischemia together raise the level of MiR-503 acutely but it does not remain at high level after 3 months. Although higher miR was related to more disability in acute phase, it does not affect long-term outcome in ischemic patients. As MiR-503 is stable enough in blood it can be used as a potential diagnostic marker of an ischemic stroke in diabetic patient. Its level also is an indicator of stroke severity and patients' short-term outcome. It is recommended to study whether antagomiR-503 is a new therapeutic agent reducing the severity of and disability due to stroke.
\end{abstract}

Keywords: miR-503, MicroRNA, MiRNA, Ischemic stroke, Diabetes, Hyperglycemia, Ischemia

\section{Background}

Ischemic stroke accounts for $85 \%$ of strokes [1]. Its incidence rate and the complications have increased in previous decades [2]. Diabetes is a recognized independent risk factor of stroke. Hyperglycemia causes oxidative stress, leading to endothelial dysfunction and finally microvascular complications. The latter is the main cause of ischemic stroke [3]. Hyperglycemia confers greater recurrence rate and affects patients' outcome as well $[4,5]$. Diabetic patients with ischemic stroke are

\footnotetext{
* Correspondence: shaghayegh.haghjoo@gmail.com

${ }^{4}$ Applied Physiology Research Center, Isfahan University of Medical Sciences, Isfahan, Iran

Full list of author information is available at the end of the article
}

associated with poorer prognosis and higher mortality [5]. Stress hyperglycemia in non-diabetic patients after an ischemic stroke increases in-hospital mortality rate and diminishes functional recovery [6].

MicroRNAs are non-coding, tiny, 20-25 nucleotideslong RNAs; which bind to 3'UTR of the target mRNA leading to mRNA degradation or translation inhibition $[7,8]$. The role of microRNAs in progression of diabetes and its complications including micro- and macrovascular dysfunction has been highlighted [9]. Downregulation of MiR-126 inhibits proliferation and migration of endothelial progenitor cells [10] while expression of miR-375 plays a regulatory role in pancreatic cell proliferation and insulin secretion [11]. Studies also revealed

(c) The Author(s). 2019 Open Access This article is distributed under the terms of the Creative Commons Attribution 4.0 International License (http://creativecommons.org/licenses/by/4.0/), which permits unrestricted use, distribution, and reproduction in any medium, provided you give appropriate credit to the original author(s) and the source, provide a link to the Creative Commons license, and indicate if changes were made. The Creative Commons Public Domain Dedication waiver (http://creativecommons.org/publicdomain/zero/1.0/) applies to the data made available in this article, unless otherwise stated. 
bidirectional role of miRNAs in acute ischemic stroke pathology; neuroprotective and neuro-damaging. Therefore, two therapeutic strategies are suggested for patients with acute ischemic stroke to decrease the burden of disease; knocking down neuro-damaging miRNAs by antagomirs which neutralize the function of miRNA [9, 12-14] and discovery of neuroprotective miRNA mimics [15].

A study revealed that expression of miR-503 was significantly increased in ischemic muscles of diabetic mice and also diabetic patients undergoing foot amputation for critical ischemia. It has shown that miR-503 impairs reparative angiogenesis after limb ischemia in diabetes mellitus (DM). As evidence, inhibition of miR-503 normalizes post-ischemic blood flow and improves recovery by neovascularization in diabetic mice [16]. There is no study evaluating miR-503 expression in diabetic patients with ischemic stroke. Therefore we designed this study to see how does miR-503 level change in a diabetic patient when an ischemic stroke occurs and 3 months later. We aimed to find whether it can be used as a diagnostic marker.

\section{Methods}

This cross-sectional study was conducted in Alzahra hospital, Isfahan, Iran, 2015-2017. The medical ethics committee of Isfahan University of Medical Sciences approved the study. Study was designed to compare miR-503 level in 4 groups of diabetic patients with stroke (I), non-diabetic patients with stroke (II), diabetic patients without stroke (III) and healthy controls. Sample size for case groups was calculated to be 15 patients in each group based on Caporali et al. study [16]. Cases of groups (I) and (II) were selected consecutively from patients with ischemic stroke who were admitted to the department of neurology of Alzahra hospital within $72 \mathrm{~h}$ after symptom onset. Diabetic patients who were diagnosed according to the WHO diabetes mellitus diagnostic criteria at the health clinic of Alzahra were randomly chosen for group (III). Informed consent was obtained from participants or their next of kin if they were not conscious. Patients with any of the disease which may affect the plasma level of miR-503 including history of GI and CNS tumors, pulmonary, neurodegenerative, cardiovascular, autoimmune diseases and previous stroke within prior year did not meet inclusion criteria. Patients with ischemic stroke who were affected by post-ischemic cerebral hemorrhage or cardiac attack during their hospital stay were excluded from further analysis. Diagnosis of acute ischemic stroke was based on clinical findings and confirmed with CT/MRI scans. The extent of impairment due to stroke is measured objectively by National Institutes of Health Stroke Scale, (NIHSS). NIHSS Scoring is classified as: (0) no stroke symptom,
[1-4] mild, [5-15] moderate, [16-20] moderate to severe and [21-42] severe stroke [17]. Degree of disability in daily activities is measured by modified Rankin Scale (mRS) which runs from 0 to 6, perfect health without symptom to death. Patients with $\mathrm{mRS} \leq 2$ in acute phase were considered to have good outcome [16]. Patients were followed for a period of 3 months and long-term outcome was also evaluated by mRS again. Stroke subtypes were classified according to TOAST classification into large-artery atherosclerosis, small vessel occlusion, cardioembolism and stroke of undetermined etiology [18].

From each participant, $5 \mathrm{ml}$ of whole blood was collected into an EDTA-containing tube (BD Vacutainer, Plymouth, UK) by venipuncture. Blood samples of group (I) and (II) were obtained in the first 3 days from the onset of symptoms. Blood samples were fractionated by a centrifuge at $3000 \mathrm{~g}$ for $15 \mathrm{~min}$ at $4{ }^{\circ} \mathrm{C}$. The plasma layer was then aliquoted and stored at $-70^{\circ} \mathrm{C}$. Total RNA containing miRNAs was extracted from samples using the Qiazol reagent followed by miRNeasy mini kit according to the manufacturer protocol. Reverse transcription reactions were performed with $1 \mu \mathrm{g}$ total RNA using miScript II RT kit (Qiagen, Germany) after DNase I treatment (Ambion, USA) according to manufacturer protocol.

Real time quantitative RT-PCR was performed using ABM EvaGreen miRNA qPCR Mastermix according to the manufacturer instructions. Relative quantification was achieved by normalization to the amount of U6. All reactions were performed in triplicate. All predesigned primers for miR-503 and U6 were purchased from ABM (Applied Biological Materials, Canada). The relative gene expression levels were calculated using Relative Expression Software Tool (REST) software version 2009 (QIAGEN, Germany). Fasting blood sugar (FBS), $\mathrm{HbA1C}$, cholesterol and triglyceride were recorded from all individuals. MiR level was compared in acute and chronic phase among patients by paired t-test. Independent $T$ test and ANOVA were used for quantitative variables and chi-square was applied in qualitative variables after using Kolmogorov-Smirnov in SPSS version 22. For variables, which were not normally distributed, nonparametric tests were used. All the analyses were conducted in a blind mode.

\section{Results}

Sixty patients entered the study and allocated in 4 groups: 18 diabetic patients with stroke (I), 25 non-diabetic patients with stroke (II), 12 diabetic patients without stroke (III) and 5 healthy controls. Six patients did not fulfill the inclusion criteria (have a simultaneous GI cancer, Crohn's disease, Scleroderma, heart attack and previous stroke in prior year), 4 were 
excluded due to post stroke hemorrhage, cardiac arrest and a newly diagnosed colorectal cancer. Finally, 50 patients participated in our investigation, 15 patients group (I), 18 patients group (II), 12 patients group (III) and 5 healthy individuals. Three patients died during the period of follow up and 2 other patients did not come back to visit for unknown reason. Therefore, we could collect samples of 12 patients from group (I) and 16 patients from group (II) after 3 months (Fig. 1).

Mean age and sex distribution were not different among patients in 4 groups $(p>0.05)$. HbA1C was not significantly different between group (I) and (III). FBS level was greater in group (I) than group (II) and (IV). Serum cholesterol (Chol) and triglyceride (TG) level did not statistically differ among groups (Table 1 ).

Mean relative expression of miR-503 was $3.29 \pm 2$ in group (I), $1.88 \pm 1.4$ in group (II), $2.49 \pm 1.8$ in group (III) and $1.1 \pm 0.4$ in control group. Relative expression of miR-503 was significantly different among groups

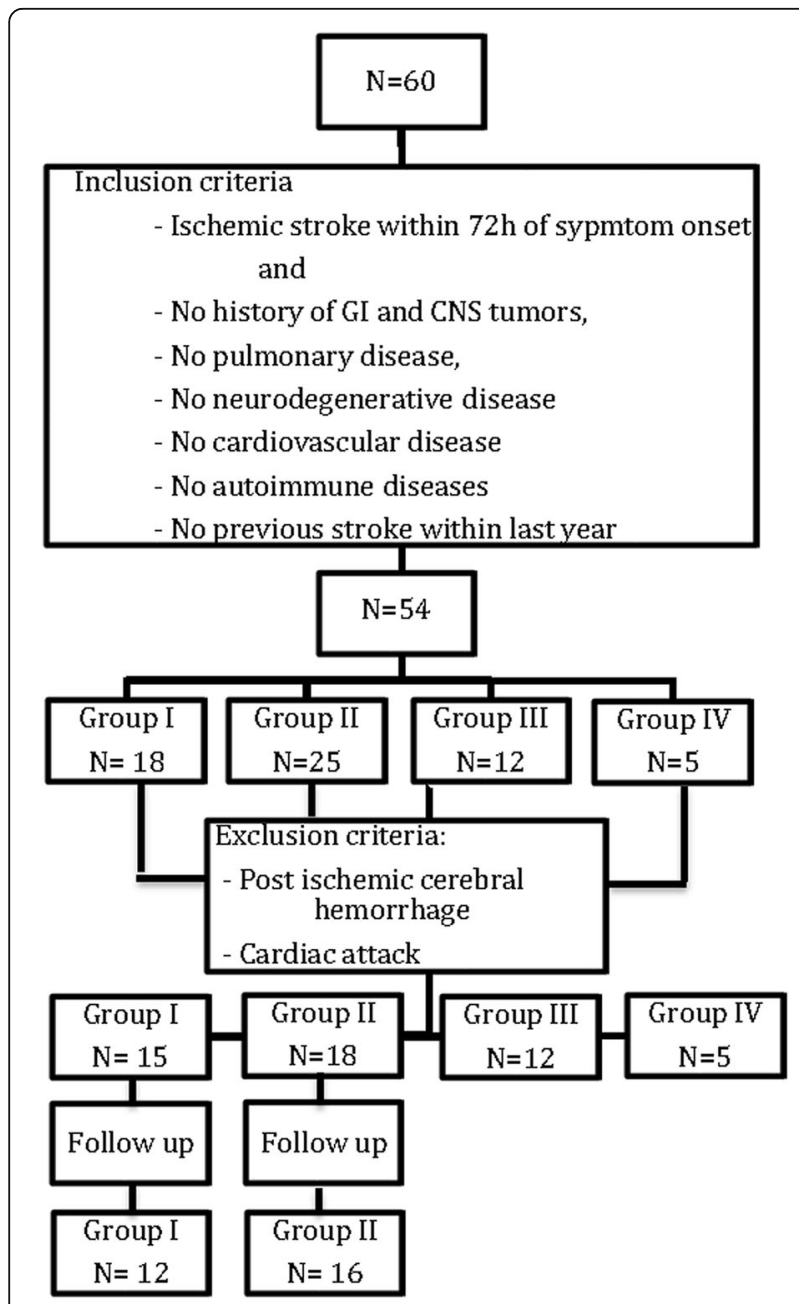

Fig. 1 The diagram shows the number of patients included in the study based on the inclusion and exclusion criteria
( $p$-value $=0.04)$. MiR-503 level was higher in diabeticstroke patients in comparison with stroke only patients and control individuals ( $p$-value $=0.02, \mathrm{p}$-value $=0.01$ ) The study was conducted in 29 females and 21 males. Mean relative expression of miR503 in males was significantly higher than females $(3.3 \pm 2$ vs. $1.9 \pm 1.3$, $p$-value $=0.01$.

Our results showed association between the level of miR-503 and FBS, Chol, NIHSS score and acute-phase $\operatorname{mRS}(\mathrm{r}=0.49 \mathrm{p}$-value $=0.001 ; \mathrm{r}=0.5 p=0.009 ; \mathrm{r}=0.45$ $p=0.009 ; \mathrm{r}=0.48 p=0.003 \mathrm{CI}=95 \%)$ but no correlation was seen between the level of miR-503 and FBS, Chol, mRS in acute-phase and NIHSS score of patients in groups (I), (II) and (III) separately.

Relative expression of miR-503 differs significantly in patients with different stroke severity according to NIHSS scoring $(p=0.02)$. The expression levels were 1.9 \pm 1.2 and $3.9 \pm 2.7$ in patients with moderate stroke and moderate to severe stroke respectively $(p=0.01)$. There was no significant difference in FBS, TG and Chol level among patients with different stroke severity. Relative expression of $\mathrm{miR}$ in patients with $\mathrm{mRS} \leq 2$ (good outcome) was $1.3 \pm 0.5$ and in patients with $\mathrm{mRS}>2$ (poor outcome) was $2.9 \pm 1.5$ in acute phase ( $p=0.008)$.

In the 2nd sampling, 3 months later, mean relative expression of miR-503 in diabetic patients with stroke and non-diabetic patients with stroke was $1.23 \pm 0.6$ and $1.4 \pm 0.4$ respectively. Relative expression of miR-503 in chronic phase was not significantly different among groups ( $p$-value> 0.05). It has been decreased significantly in group (I) $(p=0.002)$ and no statistical change in stroke only patients. Patients of group (I) had mRS score of $3.8 \pm 1.2$ in acute phase and $2 \pm 1.5$ in chronic phase $(p=0.01)$. Relative expression of $\mathrm{miR}$ in patients with $\mathrm{mRS} \leq 2$ was not different from patients with $\mathrm{mRS}>2$ in chronic phase. Mean FBS level did not differ in diabetic patients after 3 months.

Patients in all groups were not different regarding history of hypertension, hyperlipidemia, antihypertensive or antiplatelet drug history and clinical manifestation. Mean relative expression of miR-503 did not differ in patients with different clinical manifestations and various stroke subtypes. Expression of miR-503 was not different in patients with different ejection fractions. It was also equal among patients without carotid stenosis and patients with partial or total occlusion (Table 2).

\section{Discussion}

Many miRNAs have identified role in stroke emerging. A mice model trial showed post-ischemic increase in miR-200c level resulted in brain cells death [19]. Another study demonstrated that antimiRNA reduces stroke-induced brain damage and lower expression of the correspondent miRNA is related with less 
Table 1 Distribution of sex, mean age, fasting blood glucose (FBS), glycemic control (HbA1C), triglyceride (TG) and Cholesterol in all groups

\begin{tabular}{llllllll}
\hline & N & Age $($ mean \pm SD) & Sex (F/M) & FBS & HbA1C & TG & $186 \pm 108$ \\
\hline Group (I) & 15 & $64.4 \pm 12.6$ & $10 / 5$ & $194 \pm 54$ & $7.43 \pm 0.9$ & $196 \pm 51$ \\
Group (II) & 18 & $71.4 \pm 10$ & $10 / 8$ & $97 \pm 16$ & - & $126 \pm 58$ & $144 \pm 25$ \\
Group (III) & 12 & $65.5 \pm 16$ & $7 / 5$ & $162 \pm 11$ & $7.2 \pm 0.8$ & $157 \pm 29$ & $184 \pm 45$ \\
Control (IV) & 5 & $68.2 \pm 6$ & $3 / 2$ & $90 \pm 9$ & - & $118 \pm 25$ & $154 \pm 20$ \\
\hline
\end{tabular}

neurological deficit [20]. Expression of pro-inflammatory cytokines and chemokines and consequently brain damage is reduced by inhibition of miR-210 in acute phase of ischemic stroke. Conversely, an in vitro study elucidated high level of miR-210 under hypoxemic situation induces angiogenesis and neurogenesis [21]. Altered expression of miR-124 in cerebral ischemia also suggests promotion of neuronal survival in ischemic condition [22].

Peripheral blood samples of patients with acute ischemic stroke showed elevated miR-223 and miR-145 level compared to controls [23, 24]. However some studies reflected that $\mathrm{miR}$ is a repair biomarker and higher levels are accompanied with better outcome $[25,26]$. It has been suggested that miRNA has a diagnostic and prognostic value for ischemic stroke $[27,28]$. A therapeutic potential seems to be present by neutralizing miRNAs that cause neuronal death and prevent regeneration $[29,30]$.

One of the major risk factors for ischemic stroke is diabetes. MiRNA alterations in vascular endothelial cells (EC) increase stroke incidence in diabetic patients. There is only one recent animal study assessing miR-503 changes in ischemic stroke [31]. Our study is the first human investigation on miR-503 expression in cerebral ischemia plus high glucose state. We observed higher level of miR-503 in diabetic patients with stroke (group (I)) compared to stroke only patients (group II) suggesting that hyperglycemia and ischemic situation cause

Table 2 miR-503 expression and mRS in acute and chronic phase, NIHSS score, history of hypertension and hyperlipidemia, using antihypertensive and antiplatelet drugs, different clinical manifestations and stroke subtypes in all groups

\begin{tabular}{|c|c|c|c|c|c|}
\hline & Group (I) & Group (II) & Group (III) & Control & \\
\hline \multirow[t]{4}{*}{ miR-503 expression (acute) } & $3.3 \pm 2.1$ & $1.9 \pm 1.5$ & $2.5 \pm 1.8$ & $1.1 \pm 0.4$ & $P=0.045$ \\
\hline & & & & & $(I),(I I): p=0.02,(I I),(I I I): p=0.3$ \\
\hline & & & & & $(\mathrm{I}),(\mathrm{III}): p=0.2(\mathrm{II}),(\mathrm{IV}): p=0.4$ \\
\hline & & & & & (I). (IV): $p=0.016$ (III), (IV): $p=0.1$ \\
\hline \multirow[t]{4}{*}{ miR-503 expression (chronic) } & $1.2 \pm 0.6$ & $1.3 \pm 0.4$ & $2.5 \pm 1.8$ & $1.1 \pm 0.4$ & $P=0.009$ \\
\hline & & & & & $(\mathrm{I}),(\mathrm{II}): p=0.8,(\mathrm{II}),(\mathrm{III}): p=0.005$ \\
\hline & & & & & (I), (III): $p=0.004$ (II), (IV): $p=0.7$ \\
\hline & & & & & $(\mathrm{I}),(\mathrm{IV}): p=0.8$ \\
\hline NIHSS score & $12.2 \pm 5.2$ & $11.8 \pm 5.3$ & - & - & $p>0.05$ \\
\hline mRS acute & $3.4 \pm 1.2$ & $3.3 \pm 1.3$ & - & - & $p>0.05$ \\
\hline mRS chronic & $2 \pm 1.5$ & $3.2 \pm 1.9$ & - & - & $p>0.05$ \\
\hline Hypertension $(Y)$ & $11(84.6 \%)$ & $13(72.2 \%)$ & $3(25 \%)$ & $2(40 \%)$ & $p>0.05$ \\
\hline Hyperlipidemia (Y) & $5(38.5 \%)$ & $9(50 \%)$ & $4(33.3 \%)$ & $2(40 \%)$ & $p>0.05$ \\
\hline Antihypertensive drug & $10(66.6 \%)$ & $13(72.2 \%)$ & $3(25 \%)$ & $2(40 \%)$ & $p>0.05$ \\
\hline Antiplatelet drug & $6(46.2 \%)$ & $11(47.8 \%)$ & - & - & $p>0.05$ \\
\hline Clinical manifestation & & & - & - & $p>0.05$ \\
\hline Altered consciousness & $2(13.3 \%)$ & 7 (38.8\%) & & & \\
\hline Diplopia/dysarthria/facial paralysis & $10(76.9 \%)$ & $8(44.4 \%)$ & & & \\
\hline Hemiparesis/hemisensory deficit & $10(76.9 \%)$ & $13(72.2 . \%)$ & & & \\
\hline Stroke subtype & & & & & $p>0.05$ \\
\hline LVA & $6(40 \%)$ & $10(52.6 \%)$ & & & \\
\hline SVA & $8(53.3 \%)$ & $6(31.6 \%)$ & & & \\
\hline Cardioembolic & $1(6.7 \%)$ & $3(15.8 \%)$ & & & \\
\hline
\end{tabular}


overexpression of miR-503. On the other hand there was no significant difference in miR expression level among non-diabetic patients with stroke (group (II)) and diabetic only patients (group (III)) compared to control subjects. Therefor ischemia or hyperglycemia do not induce adequate change in miR-503 expression separately. The study was designed in 2 steps with the interval of 3 months, in order to compare the expression of miR-503 in acute and chronic phase. Chronic miR level in group (I) decreased to the miR level in group (II). This shows miR-503 is a biomarker of acute phase and falls to normal range by 3 months.

Caporali et al. has studied the regulation of miR-503 expression in hyperglycemic condition and observed that miR-503 is upregulated in plasma of diabetic rats with critical limb ischemia. They enhanced the expression of miR-503 using lentiviruses and found inhibited EC proliferation, migration, and network formation [32]. It has been studied that miR-503 affect cell cycle arrest through degradation of CDC25A in response to TGF- $\beta$ [33]. In ECs, MiR-503 directly downregulates CCNE1 and cdc25A in a situation mimicking ischemia and diabetes (high glucose/low growth factors). It has been demonstrated that miR-503 is involved in diabetic endothelial dysfunction [16].

We explored possible association between miRNA levels and mRS, and NIHSS too. Higher level of miR is detected in patients with more disability on daily activity. Also relative expression of miR-503 was lower in patients with good outcome $(\mathrm{mRS} \leq 2)$ rather than poor outcome $(\mathrm{mRS}>2)$. A microRNA profiling in ischemic stroke patients showed many microRNAs are downregulated in good outcome $(\mathrm{mRS}<2)$ stroke patients compared to normal controls, irrespective of stroke subtype [28]. We can hypothesize that miR-503 increases inflammation and oxidative stress, which is associated with increased risk of stroke and disability in diabetic patients. We observed patients with moderate to severe stroke showed greater level of miR as well. Since miR-503 level correlates with NIHSS score, it is suggested as a neurodamaging factor. MiR-223 was also found to have positive correlation with the severity of stroke [34].

We also aimed to know how miR level alterations affect patients' recovery few months after stroke. As mentioned previously, no correlation was found between initial miR level of the patients and their mRS in chronic phase. However, It has been shown that miR-503 might suppress post-ischemic neovascularization in diabetes mellitus. Also neutralizing miR-503 activity improved vascular healing and blood perfusion to ischemic limb $[16,32]$. So we expected to see more disability remaining after 3 months in patients who had higher initial expression of miR but we did not find relation between miR level and patients' long-term outcome.
While searching about the mechanism supporting our data, we found that in ECs exposed to high glucose, transcription of miR-503 increased and negatively affected pericytes' function [35]. In addition, miR-503 targeting E2F3, inhibits proliferation and induces apoptosis by cell cycle arrest in G0/G1 [36]. It has been recently discovered that losartan improves diabetic nephropathy by inhibiting miR-503 and there is a hypothesis that overexpression of miR-503 is one of the causes for diabetic nephropathy [37]. This finding is evidence for the role of miR-503 in diabetes related microvascular dysfunction. Another study revealed that miR-503-3p induces apoptosis in vascular smooth muscle cells $[38,39]$. As our investigation is a cross-sectional study no causality relationship could be interpreted. We only observed that miR-503 is remarkably increased in diabetic patients for whom ischemic stroke has occurred but evidences brings up the hypothesis that miR-503 may have a role in pathogenesis of ischemia in hyperglycemic state. It has been shown that fenofibrate and Brassica Oleracea,which remarkably lower the level of miR-503 in brain circulation, reduce stroke occurrence in mice., In-vitro overexpression of microRNA-503 in endothelial cells decreases cellular viability [31].

A similar study researched about miR role in acute ischemic stroke in diabetic patients showed that miR-223 and miR-246a are downregulated in hyperglycemia. This precipitates platelet activation and increases the risk of stroke. It has also suggested that platelet miRNA-223 and miR-146a are specific markers for diabetes mellitus but not for ischemic stroke [40]. Downregulation of miR-223 in plasma and platelet plus overexpression of miR-144 increased susceptibility to ischemic stroke in diabetic patients [41]. A study has found that miR29a is downregulated in simulated ischemia plus hyperglycemia and leads to angiogenesis [42].

Tan et al found miRNAs expression profile varies among different subtypes of ischemic stroke [28, 43]. We didn't discover any difference in miR-503 expression among patients with large artery atherosclerosis, small vessel occlusion, cardioembolism and undetermined but as our sample size was not large enough to do analysis in subgroups we could not rely on this finding. One of the most important limitations of our study was the small sample size. As this was the first study on this topic in human beings and only few supportive studies were conducted, It was not eligible for greater amount of funding. For this it is highly suggested to repeat this study in a larger number of patients to see whether the results are confirming. Another drawback in our study was including all diabetic patients, better to restrict only newly diagnosed diabetic patients. 


\section{Conclusion}

miR-503 is significantly overexpressed in diabetic patients with acute ischemic stroke and is stable enough in the blood to develop as potential diagnostic marker. We could not conclude that MiR-503 is involved in pathogenesis of stroke but further studies should be done to evaluate the hypothesis that miR-503 induces apoptosis and renders inflammatory response leading to ischemia. MiR level is also related to stroke severity and patients' short-term outcome. So antagomiR-503 may be a new therapeutic agent reducing severity and disability of stroke.

\section{Abbreviations}

CCNE1: cyclin E1; CDC25A: cytokine-derived cell cycle; CDK: cyclin-dependent kinase; EC: endothelial cell; miR-503: microRNA-503; mRS: modified Rankin Scale; NIHSS: National Institutes of Health Stroke Scale; TOAST: Trial of Org 10,172 in Acute Stroke Treatment

\section{Acknowledgements}

We should thank all staff and nurses of neurology ward of Alzahra hospital and other personnel of Applied Physiology Research Center.

\section{Funding}

There is no fund for the study.

\section{Availability of data and materials}

The datasets used and/or analyzed during the current study are available from the corresponding author on reasonable request.

\section{Authors' contributions}

SS was the main author and did data analyzing. MD drafted the manuscript. $\mathrm{SHJ}$ and MS made substantial contribution to the conception and design of the study respectively. SN collaborated in data interpreting and revision of the manuscript. MM and SAK contributed to data acquisition. LR and MHT contributed to data analyzing. All authors reviewed the final version of the manuscript and approved it.

\section{Ethics approval and consent to participate}

The study was approved by the medical ethics committee of Isfahan University of Medical Sciences with number ME7-600985-D11. An informed written consent was obtained from all participants or their next of kin for participation.

\section{Consent for publication}

Not applicable.

\section{Competing interests}

The authors declare that they have no competing interests.

\section{Publisher's Note}

Springer Nature remains neutral with regard to jurisdictional claims in published maps and institutional affiliations.

\footnotetext{
Author details

${ }^{1}$ Acquired Immunodeficiency Research Center, Isfahan University of Medical Sciences, Isfahan, Iran. ${ }^{2}$ Student Research Committee, Isfahan University of Medical Sciences, Isfahan, Iran. ${ }^{3}$ Isfahan Neurosciences Research Center, Isfahan University of Medical Sciences, Isfahan, Iran. ${ }^{4}$ Applied Physiology Research Center, Isfahan University of Medical Sciences, Isfahan, Iran. ${ }^{5}$ Mashhad University of Medical Sciences, Mashhad, Iran. ${ }^{6}$ Isfahan University of Medical Sciences, Isfahan, Iran.
}

Received: 12 November 2018 Accepted: 15 April 2019

Published online: 29 April 2019

\section{References}

1. Feigin VL, Lawes CM, Bennett DA, Barker-Collo SL, Parag V. Worldwide stroke incidence and early case fatality reported in 56 population-based studies: a systematic review. The Lancet Neurology. 2009;8(4):355-69 PubMed PMID: 19233729.

2. Krishnamurthi RV, Feigin VL, Forouzanfar MH, Mensah GA, Connor M Bennett DA, et al. Global and regional burden of first-ever ischaemic and haemorrhagic stroke during 1990-2010: findings from the Global Burden of Disease Study 2010. The Lancet Global health. 2013;1(5):e259-81 PubMed PMID: 25104492. Pubmed Central PMCID: 4181351.

3. Ferreiro JL, Gomez-Hospital JA, Angiolillo DJ. Platelet abnormalities in diabetes mellitus. Diab Vasc Dis Res. 2010;7(4):251-9 PubMed PMID: 20921090.

4. Shou J, Zhou L, Zhu S, Zhang X. Diabetes is an independent risk factor for stroke recurrence in stroke patients: a meta-analysis. J Stroke Cerebrovasc Dis. 2015;24(9):1961-8 PubMed PMID: 26166420.

5. Chen R, Ovbiagele B, Feng W. Diabetes and stroke: epidemiology, pathophysiology, pharmaceuticals and outcomes. Am J Med Sci. 2016; 351(4):380-6 PubMed PMID: 27079344. Pubmed Central PMCID: 5298897.

6. Capes SE, Hunt D, Malmberg K, Pathak P, Gerstein HC. Stress hyperglycemia and prognosis of stroke in nondiabetic and diabetic patients: a systematic overview. Stroke. 2001;32(10):2426-32 PubMed PMID: 11588337.

7. Kong YW, Cannell IG, de Moor CH, Hill K, Garside PG, Hamilton TL, et al. The mechanism of micro-RNA-mediated translation repression is determined by the promoter of the target gene. Proc Natl Acad Sci U S A. 2008;105(26): 8866-71 PubMed PMID: 18579786. Pubmed Central PMCID: 2449332.

8. O'Brien J, Hayder H, Zayed Y, Peng C. Overview of MicroRNA biogenesis, mechanisms of actions, and circulation. Front Endocrinol (Lausanne). 2018:9:402 Pubmed PMID: 30123182.

9. Koutsis G, Siasos G, Spengos K. The emerging role of microRNA in stroke. Curr Top Med Chem. 2013;13(13):1573-88 PubMed PMID: 23745809.

10. Meng S, Cao JT, Zhang B, Zhou Q, Shen CX, Wang CQ. Downregulation of microRNA-126 in endothelial progenitor cells from diabetes patients, impairs their functional properties, via target gene Spred-1. J Mol Cell Cardiol. 2012;53(1):64-72 PubMed PMID: 22525256

11. Li X. MiR-375, a microRNA related to diabetes. Gene. 2014:533(1):1-4 PubMed PMID: 24120394.

12. Dharap A, Bowen K, Place R, Li LC, Vemuganti $R$. Transient focal ischemia induces extensive temporal changes in rat cerebral microRNAome. J Cereb Blood Flow Metab. 2009;29(4):675-87 PubMed PMID: 19142192. Pubmed Central PMCID: 2743462

13. Yin KJ, Deng Z, Huang H, Hamblin M, Xie C, Zhang J, et al. miR-497 regulates neuronal death in mouse brain after transient focal cerebral ischemia. Neurobiol Dis. 2010;38(1):17-26 PubMed PMID: 20053374. Pubmed Central PMCID: 2837803.

14. Ouyang YB, Lu Y, Yue $S, X u L$, Xiong $X X$, White $R E$, et al. miR-181 regulates GRP78 and influences outcome from cerebral ischemia in vitro and in vivo. Neurobiol Dis. 2012:45(1):555-63 PubMed PMID: 21983159. Pubmed Central PMCID: 3251314

15. Buller B, Liu X, Wang X, Zhang RL, Zhang L, Hozeska-Solgot A, et al. MicroRNA-21 protects neurons from ischemic death. The FEBS journal. 2010; 277(20):4299-307 PubMed PMID: 20840605. Pubmed Central PMCID: 2957309

16. Caporali A, Meloni M, Vollenkle C, Bonci D, Sala-Newby GB, Addis R, et al. Deregulation of microRNA-503 contributes to diabetes mellitus-induced impairment of endothelial function and reparative angiogenesis after limb ischemia. Circulation. 2011;123(3):282-91 PubMed PMID: 21220732.

17. $\mathrm{VH}$. The $\mathrm{NIH}$ stroke scale: a window into neurological status. Nursing Spectrum 2011;24(15):44-49.

18. Adams HP Jr, Bendixen BH, Kappelle LJ, Biller J, Love BB, Gordon DL, et al. Classification of subtype of acute ischemic stroke. Definitions for use in a multicenter clinical trial. TOAST. Trial of org 10172 in acute stroke treatment. Stroke. 1993;24(1):35-41 PubMed PMID: 7678184

19. Stary CM, Xu L, Sun X, Ouyang YB, White RE, Leong J, et al. MicroRNA-200C contributes to injury from transient focal cerebral ischemia by targeting Reelin. Stroke. 2015:46(2):551-6 PubMed PMID: 25604249. Pubmed Central PMCID: 4346276. 
20. Vinciguerra A, Formisano L, Cerullo P, Guida N, Cuomo O, Esposito A, et al. MicroRNA-103-1 selectively downregulates brain NCX1 and its inhibition by anti-miRNA ameliorates stroke damage and neurological deficits. Mol Ther. 2014:22(10):1829-38 PubMed PMID: 24954474. Pubmed Central PMCID: 4428397.

21. Zeng $L$, He $X$, Wang $Y$, Tang $Y$, Zheng C, Cai H, et al. MicroRNA-210 overexpression induces angiogenesis and neurogenesis in the normal adult mouse brain. Gene Ther. 2014;21(1):37-43 PubMed PMID: 24152581.

22. Doeppner TR, Doehring M, Bretschneider E, Zechariah A, Kaltwasser B, Muller B, et al. MicroRNA-124 protects against focal cerebral ischemia via mechanisms involving Usp14-dependent REST degradation. Acta Neuropathol. 2013;126(2):251-65 PubMed PMID: 23754622.

23. Hughes JM, Seale JP, Temple DM. Ranitidine does not potentiate mediator release from human lung in vitro. Br J Clin Pharmacol. 1985;19(5):711-2 PubMed PMID: 2408646. Pubmed Central PMCID: 1463835.

24. Gan CS, Wang CW, Tan KS. Circulatory microRNA-145 expression is increased in cerebral ischemia. Genet Mol Res. 27(11, 1):147-52 PubMed PMID: 22370881

25. Zeng L, Liu J, Wang Y, Wang L, Weng S, Chen S, et al. Cocktail blood biomarkers: prediction of clinical outcomes in patients with acute ischemic stroke. Eur Neurol. 2013;69(2):68-75 PubMed PMID: 23154383.

26. Zeng $L$, Liu J, Wang $Y$, Wang $L$, Weng $S$, Tang $Y$, et al. MicroRNA-210 as a novel blood biomarker in acute cerebral ischemia. Frontiers in bioscience 2011 Jun. 1(3):1265-72 PubMed PMID: 21622133.

27. Sepramaniam S, Tan JR, Tan KS, DeSilva DA, Tavintharan S, Woon FP, et al. Circulating microRNAs as biomarkers of acute stroke. Int J Mol Sci. 2014; 15(1):1418-32 PubMed PMID: 24447930. Pubmed Central PMCID: 3907877.

28. Tan KS, Armugam A, Sepramaniam S, Lim KY, Setyowati KD, Wang CW, et al. Expression profile of MicroRNAs in young stroke patients. PLoS One 2009; 4(11):e7689. PubMed PMID: 19888324. Pubmed Central PMCID: 2765616.

29. Chen J, Yang T, Yu H, Sun $K$, Shi Y, Song W, et al. A functional variant in the 3'-UTR of angiopoietin-1 might reduce stroke risk by interfering with the binding efficiency of microRNA 211. Hum Mol Genet. 2010;19(12):2524-33 PubMed PMID: 20378606.

30. Vemuganti R. All's well that transcribes well: non-coding RNAs and poststroke brain damage. Neurochem Int. 2013;63(5):438-49 PubMed PMID: 23954844. Pubmed Central PMCID: 3805745.

31. Rubattu S, Stanzione R, Bianchi F, Cotugno M, Forte M, Della Ragione F, et al. Reduced brain UCP2 expression mediated by microRNA-503 contributes to increased stroke susceptibility in the high-salt fed stroke-prone spontaneously hypertensive rat. Cell Death Dis. 2017;8(6):e2891 PubMed PMID: 28640254. Pubmed Central PMCID: 5520932.

32. Caporali A, Emanueli C. MicroRNA-503 and the extended microRNA-16 family in angiogenesis. Trends in cardiovascular medicine. 2011;21(6):162-6 PubMed PMID: 22814423. Pubmed Central PMCID: 3407871

33. Llobet-Navas D, Rodriguez-Barrueco R, de la Iglesia-Vicente J, Olivan M, Castro V, Saucedo-Cuevas L, et al. The microRNA 424/503 cluster reduces CDC25A expression during cell cycle arrest imposed by transforming growth factor beta in mammary epithelial cells. Mol Cell Biol. 2014;34(23): 4216-31 PubMed PMID: 25266660. Pubmed Central PMCID: 4248740.

34. Chen $Y$, Song $Y$, Huang J, Qu M, Zhang Y, Geng J, et al. Increased circulating Exosomal miRNA-223 is associated with acute ischemic stroke. Front Neurol. 2017:8:57 PubMed PMID: 28289400. Pubmed Central PMCID: 5326773.

35. Caporali A, Meloni M, Nailor A, Mitic T, Shantikumar S, Riu F, et al. p75(NTR)dependent activation of NF-kappaB regulates microRNA-503 transcription and pericyte-endothelial crosstalk in diabetes after limb ischaemia. Nat Commun. 2015;6:8024 PubMed PMID: 26268439. Pubmed Central PMCID: 4538859.

36. Chang SW, Yue J, Wang BC, Zhang XL. miR-503 inhibits cell proliferation and induces apoptosis in colorectal cancer cells by targeting E2F3, 12853. Int J Clin Exp Pathol. 2015;8(10):-60 PubMed PMID: 26722476. Pubmed Central PMCID: 4680421.

37. Zhu X, Zhang C, Fan Q, Liu X, Yang G, Jiang Y, et al. Inhibiting MicroRNA503 and MicroRNA-181d with Losartan Ameliorates Diabetic Nephropathy in KKAy Mice. Med Sci Monit. 2016;22:3902-9 PubMed PMID: 27770539. Pubmed Central PMCID: 5081237.

38. Kavurma MM, Khachigian LM. Sp1 inhibits proliferation and induces apoptosis in vascular smooth muscle cells by repressing p21WAF1/Cip1 transcription and cyclin D1-Cdk4-p21WAF1/Cip1 complex formation. J Biol Chem. 2003;278(35):32537-43 PubMed PMID: 12796485.
39. Harper JW, Adami GR, Wei N, Keyomarsi K, Elledge SJ. The p21 Cdkinteracting protein Cip1 is a potent inhibitor of G1 cyclin-dependent kinases. Cell. 1993;75(4):805-16 PubMed PMID: 8242751.

40. Duan X, Zhan Q, Song B, Zeng S, Zhou J, Long Y, et al. Detection of platelet microRNA expression in patients with diabetes mellitus with or without ischemic stroke. J Diabetes Complicat. 2014;28(5):705-10 PubMed PMID: 24908639

41. Yang S, Zhao J, Chen Y, Lei M. Biomarkers associated with ischemic stroke in diabetes mellitus patients. Cardiovasc Toxicol. 2016;16(3):213-22 PubMed PMID: 26175178.

42. Chen L, Okeke E, Ayalew D, Wang D, Shahid L, Dokun AO. Modulation of miR29a improves impaired post-ischemic angiogenesis in hyperglycemia. Exp Biol Med. 2017;242(14):1432-43 PubMed PMID: 28637396. Pubmed Central PMCID: 5544167.

43. Tan JR, Tan KS, Koo YX, Yong FL, Wang CW, Armugam A, et al. Blood microRNAs in low or no risk ischemic stroke patients. Int J Mol Sci. 2013; 14(1):2072-84 PubMed PMID: 23340648. Pubmed Central PMCID: 3565366.

\section{Ready to submit your research? Choose BMC and benefit from:}

- fast, convenient online submission

- thorough peer review by experienced researchers in your field

- rapid publication on acceptance

- support for research data, including large and complex data types

- gold Open Access which fosters wider collaboration and increased citations

- maximum visibility for your research: over $100 \mathrm{M}$ website views per year

At $\mathrm{BMC}$, research is always in progress.

Learn more biomedcentral.com/submissions 